\title{
Haemodynamic effects of intravenous morphine in patients with acute myocardial infarction complicated by severe left ventricular failure
}

\section{Summary and conclusions}

The haemodynamic effects of intravenous morphine sulphate $(0.2 \mathrm{mg} / \mathrm{kg}$ body weight) were measured in 10 patients with acute myocardial infarction complicated by severe left ventricular failure. Fifteen minutes after morphine injection there was a significant fall in mean heart rate (from 108 to 101 beats/min) and mean systemic arterial pressure (from 80 to $65 \mathrm{~mm} \mathrm{Hg}$ ), and a small fall in mean cardiac index (from $2 \cdot 4$ to $2 \cdot 21 / \mathrm{min} / \mathrm{m}^{2}$ ). Haemodynamic changes at 45 minutes were similar. Neither stroke index nor indirect left ventricular filling pressure (measured as pulmonary artery end-diastolic pressure) were consistently improved 15 or 45 minutes after injection.

The useful action of morphine in relieving distressing cardiac dyspnoea is not adequately explained by systemic venous blood pooling. These results suggest that the effects of morphine on the central nervous system are more important.

\section{Introduction}

Left ventricular failure complicating myocardial infarction is usually treated with morphine because of the beneficial action of this drug in relieving cardiac pain and dyspnoea. Although the haemodynamic effects of morphine in acute myocardial infarction are well defined, ${ }^{1-4}$ we are not aware of any study restricted to patients with severe left ventricular failure. Thus morphine's mechanism of action in this condition is not known, ${ }^{5}$ but extrapolation from experimental studies ${ }^{6-8}$ and evidence in man $^{9-11}$ suggests that peripheral venous pooling with consequent reduction of left ventricular filling pressure may be important. We attempted to determine how effectively intravenous morphine could reduce left ventricular filling pressure in patients with acute myocardial infarction complicated by severe left ventricular failure.

\section{Patients and methods}

Ten male patients were studied within 72 hours of admission to the coronary care unit. Their average age was 69 years (range 55-85). All showed electrocardiographic evidence of acute infarction (two inferior and eight anterior), were in sinus rhythm, and showed radiographic evidence of pulmonary oedema. Five had proved

Department of Cardiology, Royal Sussex County Hospital, Brighton BN2 5BE

A D TIMMIS, MB, MRCP, registrar (present address: King's College Hospital, London SE5 9RS)

$M$ T ROTHMAN, MB, MRCP, registrar (present address: Stanford University, California, USA)

M A HENDERSON, $M B$, research senior house officer (present address: Toronto General Hospital, Toronto, Canada)

D A CHAMBERLAIN, MD, FRCP, consultant cardiologist

Department of Biochemistry, Hurstwood Park Neurological Centre, Haywards Heath, West Sussex RH17 7S J

P W GEAL, FIMLS, chief technician resistant to treatment with digoxin and diuretics. None of the patients was receiving any other cardioactive drug, and no patient had received diuretics or opiates in the four hours before the investigation. A Swan-Ganz thermodilution catheter (Edwards Laboratories) was inserted into the subclavian vein and flow-guided with continuous pressure monitoring into the pulmonary artery, and a short cannula (19 gauge) was inserted into the radial artery. During these procedures the patients reclined at $45^{\circ}$, and pressures were measured with reference to sternal angle with a Statham $\mathrm{P} 23 \mathrm{Db}$ transducer. Recordings were made on a fibreoptic medical recorder (Cambridge Scientific Instruments). Cardiac output was measured by the thermodilution technique using an Edwards computer model 9510-A.

After a rest period of 30 minutes morphine $0.2 \mathrm{mg} / \mathrm{kg}$ body weight was injected into the right atrium over five minutes (mean dose $15 \mathrm{mg}$ ). Haemodynamic measurements were made immediately before the morphine injection (control value) and again 15 and 45 minutes afterwards; in seven patients further measurements were made at four hours. In six patients an indwelling catheter enabled hourly measurements of urine output to be made. Serum morphine concentrations were estimated by a morphine-specific spectrofluorimetric technique ${ }^{12}$ in blood samples collected when haemodynamic observations were made.

All of the patients had severe left ventricular failure, and in such patients pulmonary artery pressure monitoring is routinely used by us to guide treatment. Because intravenous morphine is part of our conventional treatment only informal consent was obtained after the purpose of the treatment and observations had been explained. We did not wish to increase anxiety by unnecessarily requesting written consent from critically ill patients. The protocol was approved by the ethical committee.

Student's $t$ test for paired data was used for statistical comparisons.

\section{Results}

All patients became drowsy and apparently less dyspnoeic within a few minutes of having the morphine but remained rousable.

Table I shows the haemodynamic effects of the morphine, and table II shows that pulmonary artery end-diastolic pressure fell in seven of the 10 patients; in no patient was the fall greater than $6 \mathrm{~mm} \mathrm{Hg}$, and the mean reduction for the group was only $2 \mathrm{~mm} \mathrm{Hg}$. This was not significant. A small but progressive decrease in heart rate occurred in all patients, the rate falling from 108 beats/ min just before morphine injection to 97 beats/min 45 minutes afterwards. Mean systemic arterial pressure also fell significantly (from 80 to $67 \mathrm{~mm} \mathrm{Hg}$ ); since mean cardiac index showed only a small reduction, systemic vascular resistance fell only slightly. Stroke index was unaffected by morphine.

TABLE I-Haemodynamic variables before and after morphine injection in 10 patients. Results expressed as means $\pm S E M$

\begin{tabular}{|c|c|c|c|c|}
\hline \multirow{2}{*}{ Variable } & & \multirow{2}{*}{ Control } & \multicolumn{2}{|c|}{ Min after injection } \\
\hline & & & 15 & 45 \\
\hline 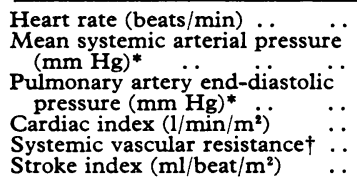 & $\begin{array}{l}\cdots \\
\cdots \\
\cdots \\
\cdots \\
\cdots\end{array}$ & $\begin{aligned} 108 & \pm 5 \\
80 & \pm 6 \\
23 & \pm 1 \\
2 \cdot 4 & \pm 0 \cdot 2 \\
19 & \pm 2 \\
22 & \pm 2\end{aligned}$ & $\begin{aligned} 101 & \pm 6 \\
65 & \pm 4 \uparrow \\
21 & \pm 2 \\
2 \cdot 2 & \pm 2 \ddagger \\
17 & \pm 2 \S \\
22 & \pm 2\end{aligned}$ & $\begin{array}{l}97 \pm 6 ף \\
67 \pm 4 \ddagger \\
21 \pm 2 \\
2 \cdot 1 \pm 0 \cdot 2 \\
18 \pm 2 \\
22 \pm 2\end{array}$ \\
\hline
\end{tabular}

*Pressures recorded with reference to sternal angle; reference to mid-chest would require addition of about $5 \mathrm{~mm} \mathrm{Hg}$.

† Arbitrary units expressing ratio of mean systemic arterial pressure $(\mathrm{mm} \mathrm{Hg})$ : mean cardiac output $(1 / \mathrm{min})$

Differences between control value and value after injection significant at: $\neq p<0.05$, $\$ p<0.02, \| p<0.01, \pi p<0.001$. 
Mean serum morphine concentrations at 15 and 45 minutes were 0.32 and $0.20 \mathrm{mg} / 1$ respectively. The seven patients for whom results at four hours were available had considerably lower morphine concentrations at that time (mean $0.09 \mathrm{mg} / \mathrm{l}$ ); this was reflected by a tendency for haemodynamic variables to revert towards control values (table III).

Table IV shows that urine output, measured in six patients, declined from a mean of 59 to $33 \mathrm{ml} / \mathrm{h}$ over the four hours after the morphine injections.

TABLE II-Pulmonary artery end-diastolic pressure before and after morphine injection

\begin{tabular}{ccc}
\hline \multirow{2}{*}{ Case } & \multicolumn{2}{c}{ Pressure $(\mathrm{mm} \mathrm{Hg})^{*}$} \\
\cline { 2 - 3 } & Control & After 15 min \\
\hline 1 & 20 & 17 \\
2 & 20 & 24 \\
3 & 16 & 14 \\
4 & 23 & 22 \\
5 & 18 & 18 \\
6 & 25 & 22 \\
7 & 21 & 16 \\
8 & 25 & 27 \\
9 & 25 & 23 \\
10 & 32 & 21 \\
\hline Mean & 23 & \\
\hline
\end{tabular}

*Pressures recorded with reference to sterna angle; reference to mid-chest would require addition of about $5 \mathrm{~mm} \mathrm{Hg}$.

TABLE III-Haemodynamic variables and serum morphine concentrations before and after morphine injection in seven patients in whom measurements were made at four hours. Results expressed as means $\pm S E M$

\begin{tabular}{|c|c|c|c|c|c|}
\hline \multirow{2}{*}{\multicolumn{2}{|c|}{ Variable }} & \multirow{2}{*}{ Control } & \multicolumn{3}{|c|}{ Min after injection } \\
\hline & & & 15 & 45 & 240 \\
\hline \multirow{3}{*}{\multicolumn{2}{|c|}{ 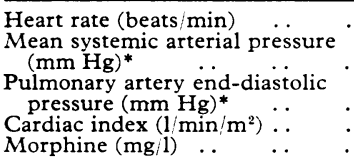 }} & $106 \pm 7$ & $98 \pm 9$ & $95 \pm 10$ & $102 \pm 6$ \\
\hline & & $87 \pm 7$ & $69=5$ & $70 \pm 5$ & $78 \pm 8$ \\
\hline & & $\begin{array}{c}20 \pm 1 \\
2 \cdot 6 \pm 0 \cdot 2 \\
0\end{array}$ & $\begin{aligned} 19 & \pm 1 \\
2 \cdot 4 & \pm 0 \cdot 2 \\
0 \cdot 32 & \pm 0 \cdot 07\end{aligned}$ & $\begin{aligned} 18 & \pm 2 \\
2 \cdot 4 & \pm 0 \cdot 1 \\
0 \cdot 22 & \pm 0.07\end{aligned}$ & $\begin{array}{c}22 \pm 1 \\
2.5 \pm 0.1 \\
0.09 \pm 0.05\end{array}$ \\
\hline
\end{tabular}

*Pressures recorded with reference to sternal angle; reference to mid-chest would require addition of about $5 \mathrm{~mm} \mathrm{Hg}$.

TABLE IV-Urine output before and after morphine injection in six patients. Results expressed as means $\pm S E M$

\begin{tabular}{lccccc}
\hline & Control & \multicolumn{4}{c}{ Hours after injection } \\
\cline { 3 - 6 } & & 1 & 2 & 3 & 4 \\
\hline Urine output $(\mathrm{ml} / \mathrm{min})$ & $59 \pm 12$ & $49 \pm 7$ & $37 \pm 10$ & $36 \pm 11$ & $33 \pm 8 \cdot 7$
\end{tabular}

\section{Discussion}

Morphine is an effective analgesic in patients with acute myocardial infarction, and in the presence of pulmonary oedema will often relieve distressing dyspnoea. How morphine acts in pulmonary oedema is not known. The subjective effects due to respiratory depression and relief of anxiety are generally believed to be useful. ${ }^{13}$ Many investigators ${ }^{6-8}$ regard reduction of venous tone with pooling of blood in the systemic circulation as of prime importance; this would lead to reduced venous return to the right heart and reduced right ventricular output, which would allow the failing left ventricle to operate at a lower filling pressure. There is little compelling evidence, however, that morphine causes either major venous pooling in the systemic circulation ${ }^{9}{ }^{10}$ or significant reduction of left ventricular filling pressure in patients with severe coronary artery disease. ${ }^{414-16}$

The patients we investigated had suffered a recent acute myocardial infarction and differed from those studied elsewhere in that they all had severe pulmonary oedema. We found no significant reduction in indirect left ventricular filling pressure (measured as pulmonary artery end-diastolic pressure), so it is unlikely that morphine causes appreciable systemic venous pooling unless the drug concurrently impairs myocardial performance.

We believe that this combination of effects may occur to a small degree. The appreciable reduction in mean systemic arterial pressure induced by morphine in our patients was probably caused partly by peripheral arteriolar dilatation. ${ }^{917}$ If this had been the only effect the reduction in left ventricular afterload would have increased cardiac output, yet we observed a small fall. This apparent paradox is resolved by the findings of Zelis et al, ${ }^{9}$ who concluded that the peripheral arteriolar and venous dilator effects of morphine are mediated by attenuation of sympathetic efferent discharge in the central nervous system. Thus in our patients any tendency for cardiac output to increase with reduction of afterload would be counteracted by withdrawal of sympathetic drive to the myocardium, as reflected by the significant reduction in heart rate after administration of morphine. In severe heart failure myocardial sympathetic withdrawal may thus impair myocardial performance, which may contribute to the hypotensive effect of the drug.

Withdrawal of sympathetic drive to the failing heart and systemic venodilatation would tend to have opposing actions on left ventricular filling pressure, with little resultant change in the pulmonary artery end-diastolic pressure if both actions were of a similarly small degree. Our results, therefore, do not exclude some venous pooling, ${ }^{18}$ but this cannot be of major haemodynamic importance.

The reduction in urine output after administration of morphine probably reflects the drug's stimulation of antidiuretic hormone secretion. ${ }^{19}$ The combination of a small reduction in cardiac output and peripheral arteriolar dilatation may also have influenced renal blood flow. Oliguria must delay the beneficial effects of diuretics on left ventricular filling pressure.

We emphasise that relief of cardiac dyspnoea by morphine is so effective that opiates should remain a first-line treatment when pulmonary oedema complicates acute myocardial infarction. Our findings do not permit full analysis of the beneficial effects of opiates, but we have little doubt that their actions on the central nervous system play the major part.

This work was partly supported by research grants from Glaxo Group Research.

Requests for reprints should be addressed to Dr D A Chamberlain.

\section{References}

1 Thomas M, Malmcrona R, Fillmore S, Shillingford J. Haemodynamic effects of morphine in patients with acute myocardial infarction. Br Heart $\mathcal{f} 1965 ; 27: 863-75$.

${ }^{2}$ Lal S, Savidge RS, Chhabra GP. Cardiovascular and respiratory effects of morphine and pentazocine in patients with myocardial infarction. Lancet 1969 ; : $: 379-81$.

${ }^{3}$ Scott ME, Orr R. Effects of diamorphine, methadone, morphine, and pentazocine in patients with suspected acute myocardial infarction. Lancet $1969 ; \mathrm{i}: 1065-7$.

${ }^{4}$ Lee G, DeMaria AN, Amsterdam EA, et al. Comparative effects of morphine, meperidine and pentazocine on cardiocirculatory dynamics in patients with acute myocardial infarction. Am $\mathcal{F}$ Med 1976;60:949-55.

${ }^{5}$ Robin ED, Cross CE, Zelis R. Pulmonary edema. 2. N Engl f Med 1973; 288:292-304.

${ }^{6}$ Henney RP, Vasko JS, Brawley RK, Oldham HN, Morrow AG. The effects of morphine on the resistance and capacitance vessels of the peripheral circulation. Am Heart $\mathcal{F} 1966$;72:242-50.

7 Vasko JS, Henney RP, Oldham HN, Brawley RK, Morrow AG. Mechanisms of action of morphine in the treatment of experimental pulmonary edema. Am $\mathcal{F}$ Cardiol 1966;18:876-83.

${ }^{8}$ Ward JM, McGrath RL, Weil JV. Effects of morphine on the peripheral vascular response to sympathetic stimulation. $A m \mathcal{F}$ Cardiol 1972; $29: 659-66$.

${ }^{9}$ Zelis R, Mansour EJ, Capone RJ, Mason DT. The cardiovascular effects of morphine. The peripheral capacitance and resistance vessels in human subjects. $\mathcal{F}$ Clin Invest 1974 ;54:1247-58.

${ }^{10}$ Vismara LA, Leaman DM, Zelis R. The effects of morphine on venous tone in patients with acute pulmonary edema. Circulation $1976 ; 54: 335-7$.

${ }^{11}$ Leaman DM, Levenson L, Zelis R, Shiroff R. Effect of morphine on splanchnic blood flow. Br Heart F 1978;40:569-71. 
12 Kupferberg HJ, Burkhalter A, Way EL. A sensitive fluorimetric assay for morphine. Fed Proc 1963;22:249-55.

13 Ebert RV. The lung in congestive heart failure. Arch Intern Med 1961 ; 107:450-9.

14 Lappas DG, Geha D, Fischer JE, Laver MB, Lowenstein E. Filling pressures of the heart and pulmonary circulation of the patient with coronary artery disease after large intravenous doses of morphine. Anesthesiology 1975;42:153-9.

15 Moffitt EA, Tarhan S, Rudriguez R, Barnhorst DA, Pluth JR. Hemodynamic effects of morphine during and early after cardiac operations. Anesth Analg (Cleve) 1976;55:47-50.
16 Popio KA, Jackson DH, Ross AM, Schaeiner BF, Yu PN. Hemodynamic and respiratory effects of morphine and butorphanol. Clin Pharmacol Ther $1978 ; 23: 281-7$.

17 Flaim SF, Zelis R, Eisele JH. Differential effects of morphine on forearm blood flow: attenuation of sympathetic control of the cutaneous circulation. Clin Pharmacol Ther 1978;23:542-6.

18 Anonymous. Treatment for heart failure: stimulation or unloading? Lancet 1979 ;ii:777-9.

19 Goodman LS, Gilman A. The pharmacological basis of therapeutics. New York: Macmillan, 1975.

(Accepted 1 February 1980)

\section{Cholestatic jaundice caused by cloxacillin: macrophage inhibition factor test in preventing rechallenge with hepatotoxic drugs}

\section{RAFAEL ENAT, SIMON POLLACK, YEHUDITH BEN-ARIEH， ELLA LIVNI， DAVID BARZILAI}

\section{Summary and conclusions}

Severe intrahepatic cholestasis occurred in a patient after taking nitrofurantoin, ampicillin, and cloxacillin. As only nitrofurantoin was known to cause cholestasis she was given cloxacillin again two years later. The cholestasis reappeared at once. A macrophage inhibition factor test confirmed that cloxacillin was the offending drug.

Cloxacillin should be added to the growing list of drugs causing cholestasis. Inadvertent rechallenge with hepatototoxic drugs might be prevented by routine use of the macrophage inhibition factor test.

\section{Introduction}

Reports of unexpected hepatotoxicity of drugs are increasing. ${ }^{1-3}$ Penicillins, however, are rarely reported as causing liver damage, though transiently increased activities of serum aspartate and alanine transaminases (serum AST and serum ALT; SGOT and SGPT) and alkaline phosphatase have been recorded. ${ }^{4-16}$ Histologically proved anicteric hepatitis was reportedly induced by carbenicillin ${ }^{17}$ and oxacillin, ${ }^{18}$ and mild cholestasis occurred after oxacillin ${ }^{19}$ and phenoxymethylpenicillin. ${ }^{20}$ Oral penicillin also reportedly caused a chronic fluctuating cholestatic hepatitis. ${ }^{21}$

We report a case in which a second episode of severe cholestasis was shown by the macrophage inhibition factor test to have been caused by inadvertent rechallenge with cloxacillin. Hepatic damage by this drug, which is congeneric to oxacillin and differs from it only slightly, has not been reported before.

Rambam Medical Centre and Faculty of Medicine, Technion, Israel Institute of Technology, Haifa, Israel

RAFAEL ENAT, MD, senior lecturer in medicine

SIMON POLLACK, MD, lecturer in medicine

YEHUDITH BEN-ARIEH, MD, lecturer in pathology

DAVID BARZILAI, MD, professor of medicine and endocrinology

Beilinson Medical Centre, Petach Tiqva, Israel

ELLA LIVNI, PHD, head of drug allergy and autoimmunity unit

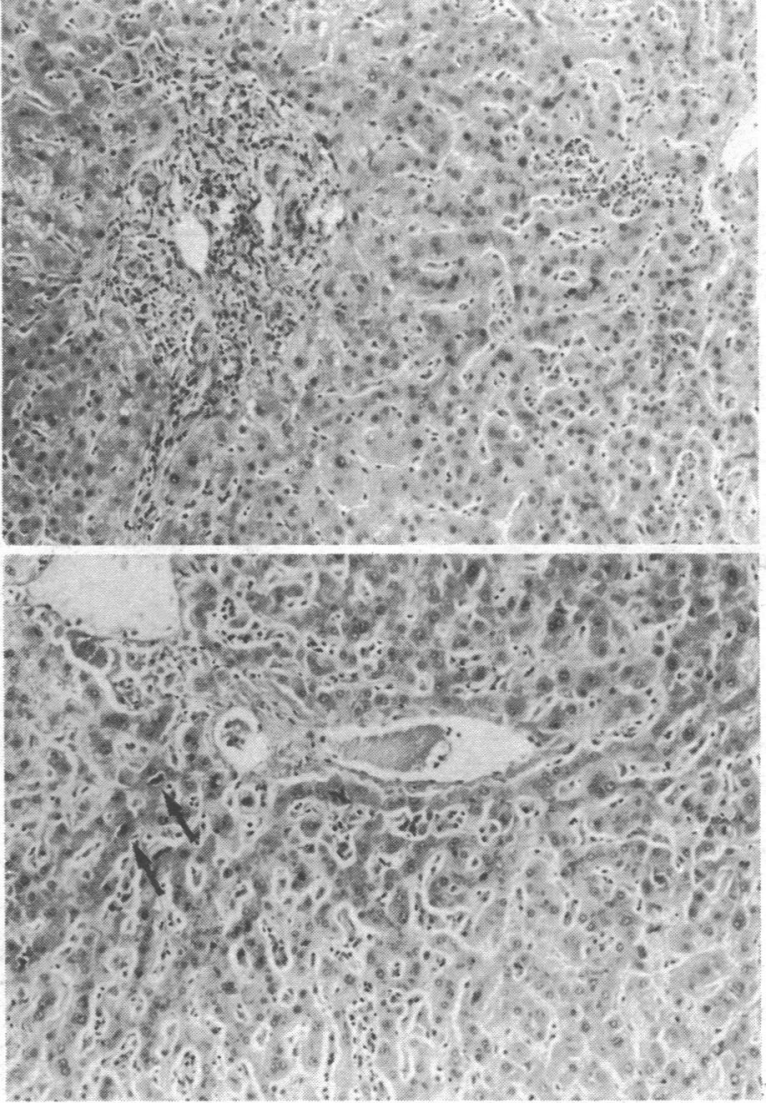

Light micrographs of wedge biopsy specimen of liver. Top: Portal space with round-cell infiltration and scattered liver cell necrosis. Bottom: Bile plugs in canaliculi (arrowed), swollen Kupffer cells, and evidence of anisocytosis. Haematoxylin and eosin $\times 100$ (original magnification).

\section{Case report}

A 69-year-old woman was admitted to hospital in 1976 with cholestatic jaundice. One month before she had been treated with nitrofurantoin for a urinary tract infection. Pneumonia was then suspected and she was given ampicillin and cloxacillin. Two weeks before admission she had begun to itch, and a few days later jaundice appeared.

On admission she had a normal temperature and showed signs of scratching all over her body. The liver was enlarged $3 \mathrm{~cm}$ below the costal margin and had a span of $15 \mathrm{~cm}$. The spleen was not palpable. Haemoglobin concentra- 